\title{
KUALITAS PAPAN KOMPOSIT BERLAPIS FINIR DARI SABUT KELAPA DAN PLASTIK POLIETILENA DAUR ULANG: VARIASI UKURAN PARTIKEL SABUT KELAPA
}

\author{
The Quality of Veneered Composite Board Made of Coir and Recycled Polyethylene: \\ Variation of coir size particle \\ Dina Setyawati, Yusuf Sudo Hadi, Muh. Yusram Massijaya, dan Naresworo Nugroho
}

\begin{abstract}
Agricultural fibers are currently used as a substituted resource to wood-based products. One of agricultural fibers that has been developed and become a resource for panel products is coir (coconut fiber). The purpose of this study is to evaluate the quality of veneered composite board made of coir and recycled polyethylene (RPE). The target density of board samples was $0.7 \mathrm{~g} / \mathrm{cm}^{3}$. The board construction type is core type composite board (three layers). Veneers from Meranti (Shorea sp.) were used as face and back layers and coir was in the core layer. RPE composition was 50\% based on coir particle and veneers oven dry weights. Recycled plastics were placed in three layers, $30 \%$ on the face and back layers, and $70 \%$ in the core layer. The coir sizes were under $1 \mathrm{~cm}, 1 \mathrm{~cm}, 5 \mathrm{~cm}, 10 \mathrm{~cm}$, and $10 \mathrm{~cm}$ up (along coir size). The composite board samples were tested by JIS A 5908 - 1994. Each parameter was measured in three replications. The research results obtained are as follows : (1) Veneered composite boards made of coir and RPE fulfill the JIS A 5908 standard in term of density, thickness swelling after 2 and 24 hours of water immersions, modulus of elasticity, modulus of rupture and internal bond, and (2) The coir size did not significantly affect the properties of composite board.
\end{abstract}

Keywords: veneered composite board, coir size, recycled polyethylene

\section{PENDAHULUAN}

Kebutuhan kayu untuk bahan baku bangunan (konstruksi) maupun untuk perabot rumah tangga terus meningkat seiring dengan meningkatnya jumlah penduduk. Di sisi lain luas dan potensi hutan yang terus menurun menyebabkan terjadinya defisit kebutuhan kayu yang jumlahnya diperkirakan mencapai 78 juta $\mathrm{m}^{3}$ per tahun (Walhi, 2004). Seiring timbulnya berbagai isu lingkungan serta tuntutan konsumen akan produk yang berkualitas, maka pemanfaatan bahan-bahan non kayu berbasis limbah, seperti sabut kelapa dan plastik daur ulang sebagai bahan baku papan komposit, dapat menjadi salah satu alternatif untuk mensubstitusi kebutuhan akan kayu sekaligus mengurangi dampak negatif terhadap lingkungan.

Potensi sabut kelapa dan plastik daur ulang di Indonesia cukup besar. Sebagai negara dengan luas perkebunan kelapa terluas di dunia, diperkirakan jumlah sabut kelapa yang dihasilkan Indonesia mencapai 1 juta ton/ tahun $(F A O, 1999)$. Pada saat ini hanya sebagian kecil sabut kelapa yang dimanfaatkan, antara lain sebagai pengisi jok mobil, kasur maupun keset. Sebagian besar sabut kelapa tersebut dibuang dan menjadi limbah. Demikian halnya plastik, dengan semakin tingginya penggunaan plastik di Indonesia, jumlah limbah plastikpun semakin meningkat. Plastik sebagai limbah akan menimbulkan dampak negatif terhadap lingkungan karena bahan tersebut sangat sulit terdekomposisi sehingga akan terus menumpuk di permukaan bumi. Namun plastik dapat didaur ulang sehingga dimungkinkan penggunaannya menjadi produk lain yang lebih bermanfaat. Beberapa penelitian yang telah dilakukan menunjukkan bahwa plastik daur ulang dapat digunakan sebagai matriks maupun pengganti perekat dalam pembuatan papan komposit (Mulyadi, 2001; Guo et al., 2004; Setyawati dan Massijaya, 2005; dan Febrianto et al., 2006).

Dari hasil penelitian Setyawati dan Massijaya (2005) diketahui bahwa papan komposit dari sabut kelapa dan plastik polipropilena daur ulang memiliki stabilitas dimensi yang tinggi, namun keteguhan lenturnya masih rendah. Dengan demikian, kualitas papan komposit tersebut perlu ditingkatkan. Salah satu 
cara untuk meningkatkan kualitas papan komposit adalah dengan penambahan bahan pelapis, misalnya finir, pada kedua permukaaan papan komposit (Massijaya, 2001; Suhasman et al., 2005 dan Nuryawan dan Massijaya, 2005). Selain itu kualitas papan komposit juga dipengaruhi oleh jenis bahan baku, perekat, kondisi pengempaan, maupun ukuran partikel yang digunakan. Karena itu dalam penelitian ini papan komposit dari sabut kelapa dan plastik polietilena (PE) daur ulang dibuat menyerupai com-ply, dan diuji kualitasnya pada berbagai ukuran sabut kelapa.

Penelitian ini bertujuan untuk mengetahui sifat fisis dan mekanis papan komposit berlapis finir dari sabut kelapa dan plastik polietilena daur ulang pada berbagai ukuran sabut kelapa, sehingga dapat ditentukan ukuran sabut kelapa yang paling optimum untuk pembuatan papan komposit. Di masa mendatang, penelitian ini diharapkan dapat memberikan alternatif substitusi kayu yang berkualitas dan dalam rangka efisiensi penggunaan kayu dan pengendalian limbah plastik.

\section{BAHAN DAN METODE}

Bahan yang digunakan dalam penelitian ini adalah serat sabut kelapa, yaitu sabut kelapa yang telah dibersihkan dari gabusnya. Serat sabut kelapa tersebut kemudian dipotong-potong menjadi partikel dengan ukuran bervariasi : lebih pendek dari $1 \mathrm{~cm}, 1 \mathrm{~cm}, 5 \mathrm{~cm}, 10 \mathrm{~cm}$, dan lebih panjang dari $10 \mathrm{~cm}$ (sepanjang sabut kelapa utuh). Partikel tersebut kemudian dikeringkan hingga mencapai kadar air $2-4 \%$. Sebagai bahan pelapis digunakan finir Meranti (Shorea sp.). Plastik PE daur ulang berbentuk pellet digunakan sebagai perekat dengan kadar $50 \%$ dari berat papan komposit.

Partikel sabut kelapa dan pellet PE daur ulang dicampur secara manual di dalam bak plastik. Setelah itu dimasukkan ke dalam pencetak lembaran untuk membentuk lembaran contoh uji dengan ukuran $30 \mathrm{~cm} \times 30 \mathrm{~cm} \times 1 \mathrm{~cm}$. Kerapatan sasaran papan komposit yang dibuat adalah $0,7 \mathrm{~g} / \mathrm{cm}^{3}$. Pada saat pembentukan lembaran, bahan pelapis ditempatkan pada permukaan atas dan bawah lembaran. Distribusi PE daur ulang dibagi atas tiga lapisan. Lapisan atas sebanyak $15 \%$, bagian tengah $70 \%$ dan bagian bawah $15 \%$ dari berat pellet.

Pengempaan panas dilakukan pada suhu $180{ }^{\circ} \mathrm{C}$ selama 20 menit dengan tekanan 25 $\mathrm{kgf} / \mathrm{cm}^{2}$. Untuk menyeragamkan kadar air lembaran papan komposit dan melepaskan tegangan sisa yang terdapat dalam lembaran sebagai akibat pengempaan panas, maka dilakukan pengkondisian selama 2 minggu.

Kualitas papan komposit yang diuji meliputi sifat fisis dan mekanis, yaitu: kerapatan, kadar air, daya serap air, pengembangan tebal, modulus elastisitas (MOE), modulus patah (MOR), dan keteguhan rekat (IB). Pengujian dilakukan berdasarkan standar JIS A 5908 (1994). Penelitian ini menggunakan rancangan acak lengkap dengan tiga kali ulangan.

\section{HASIL DAN PEMBAHASAN}

\section{Sifat Fisis}

\section{Kerapatan}

Kerapatan papan komposit merupakan salah satu sifat fisis yang sangat berpengaruh terhadap kualitas papan komposit. Karena itu kerapatan papan komposit diupayakan seseragam mungkin, sehingga perbedaan sifatsifat papan komposit yang dianalisis sedapat mungkin tidak disebabkan oleh perbedaan kerapatan. Nilai kerapatan papan komposit pada penelitian ini disajikan pada Gambar 1.

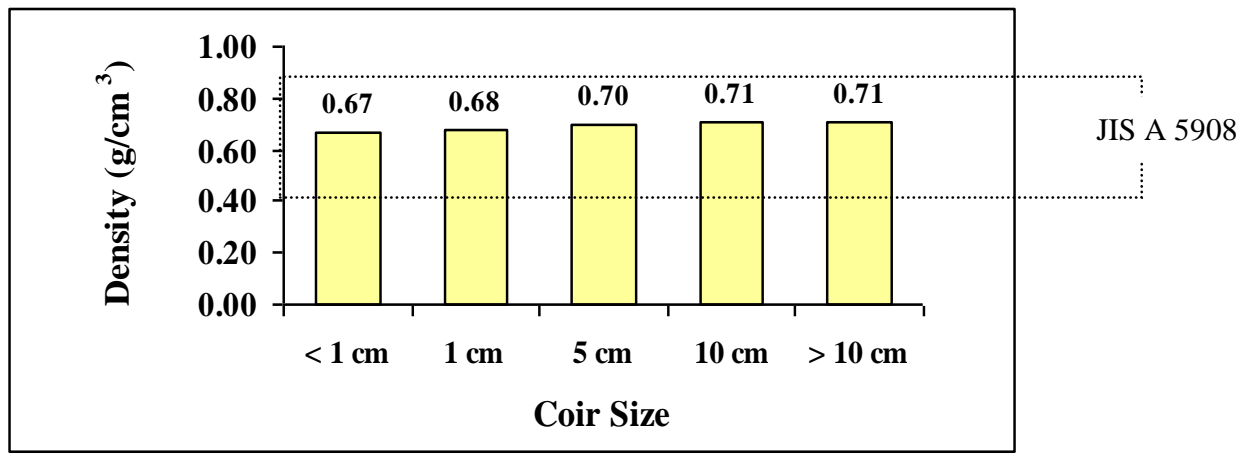

Figure 1. Composite Board Density at Different Coir Sizes 


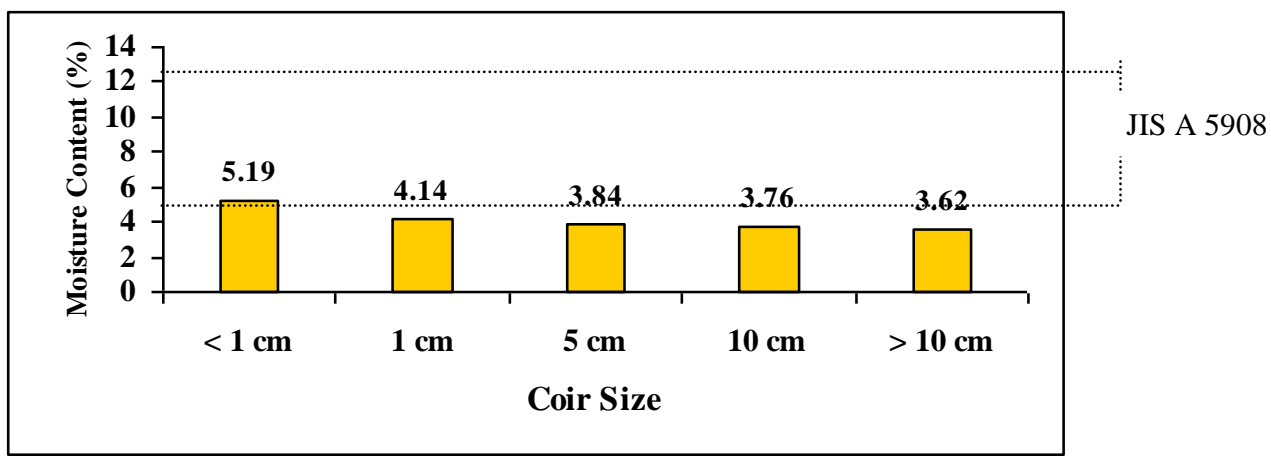

Figure 2.. Moisture Content of the Composite Board at Different Coir Size

Hasil pengujian kerapatan papan komposit pada penelitian ini relatif seragam dengan kisaran antara 0,67 sampai $0,71 \mathrm{~g} / \mathrm{cm}^{3}$. JIS 5908-1994 menetapkan kerapatan papan komposit sebesar 0,40 sampai $0,90 \mathrm{~g} / \mathrm{cm}^{3}$. Dengan demikian nilai kerapatan papan komposit pada penelitian ini seluruhnya memenuhi standar tersebut.

Hasil sidik ragam menunjukkan bahwa ukuran sabut kelapa tidak berpengaruh nyata terhadap kerapatan. Hal ini disebabkan karena kerapatan papan komposit terutama ditentukan oleh kerapatan bahan bakunya. Dalam penelitian ini jenis dan komposisi bahan baku yang digunakan sama, sehingga nilai kerapatan yang dihasilkan tidak jauh berbeda.

\section{Kadar Air}

Kadar air merupakan sifat papan komposit yang mencerminkan kandungan air papan komposit dalam keadaan kesetimbangan dengan lingkungan sekitarnya. Hasil pengujian kadar air papan komposit pada penelitian ini dapat dilihat pada Gambar 2.

Nilai kadar air papan komposit berkisar antara 3,62\% sampai 5,19\%. Pada Gambar 2 dapat dilihat bahwa nilai kadar air cenderung menurun dengan makin panjangnya ukuran sabut kelapa. Hal ini disebabkan karena semakin kecil ukuran partikel sabut kelapa, maka luas permukaan partikel sabut kelapa menjadi semakin besar pada volume yang sama. Dengan demikian semakin banyak uap air yang dapat diserap dari lingkungannya. Akan tetapi, dari hasil sidik ragam diketahui bahwa ukuran sabut kelapa tidak berpengaruh terhadap kadar air papan komposit.

Papan komposit pada penelitian ini mempunyai kadar air yang lebih rendah dari nilai yang dipersyaratkan JIS A 5908 (1994), yaitu 5 $13 \%$. Hasil tersebut tidak jauh berbeda dengan penelitian Mulyadi (2001) dan Setyawati dan Massijaya (2005) yang membuat papan komposit dengan menggunakan plastik polipropilena (PP) daur ulang. Rendahnya kadar air pada papan komposit tersebut disebabkan plastik daur ulang yang digunakan sebagai perekat bersifat hidrofobik, sehingga papan komposit tidak mudah menyerap uap air dari lingkungan .

\section{Daya Serap Air}

Nilai rata-rata daya serap air papan komposit yang direndam selama 2 jam dan 24 jam disajikan pada Gambar 3.

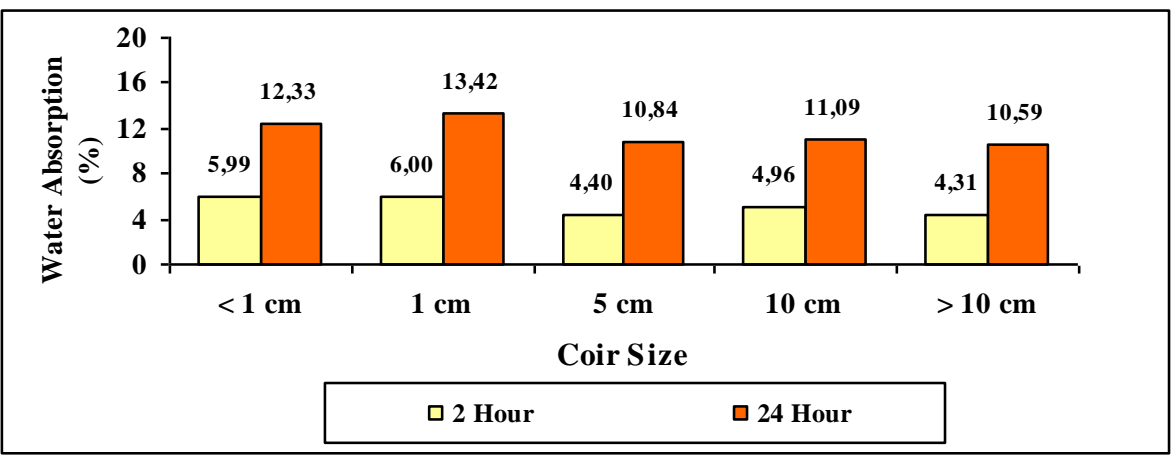

Figure 3. Water Absorption of the Composite Board after 2 and 24 Hour Water Immersion at Different Coir Size 
Daya serap air papan komposit pada penelitian ini bertambah seiring dengan pertambahan waktu perendaman papan. Nilai ratarata daya serap air papan komposit yang direndam selama 2 jam berkisar antara 4,31 sampai 6,00\%. Adapun daya serap air pada papan komposit yang direndam selama 24 jam berkisar antara 10,59\% sampai $13,42 \%$. Semakin lama waktu perendaman, semakin banyak air yang dapat diserap oleh papan komposit. Hal ini disebabkan terjadinya kerusakan ikatan rekat yang terbentuk selama proses pengempaan. Kerusakan ikatan rekat tersebut dapat terjadi akibat dari perlemahan ikatan karena pengaruh air maupun sebagai akibat dari pengembangan partikel sabut kelapa yang telah menyerap air. Namun bila dibandingkan dengan nilai daya serap air comply yang dibuat dengan perekat fenol formaldehida $(41,22 \%)$ dan melamin formaldehida $(30,07 \%)$ pada penelitian Nuryawan dan Massijaya (2005), maka daya serap air papan komposit pada penelitian ini jauh lebih kecil. Sebagaimana dikemukakan sebelumnya, hal ini disebabkan oleh sifat plastik yang hidrofobik, sehingga walaupun air masih dapat masuk melalui pori-pori papan komposit, namun jumlahnya tidak terlalu besar.

Walaupun terdapat variasi nilai daya serap air pada papan komposit yang dihasilkan, namun hasil sidik ragam menunjukkan bahwa ukuran sabut kelapa tidak berpengaruh nyata terhadap daya serap air papan komposit setelah direndam selama 2 jam dan 24 jam.

\section{Pengembangan Tebal}

Nilai rata-rata pengembangan tebal papan komposit setelah direndam selama 2 jam dan 24 jam dalam air pada suhu kamar disajikan pada Gambar 4.

Pengembangan tebal papan komposit setelah direndam selama 2 jam bervariasi antara $0,31 \%$ sampai $0,49 \%$, dan setelah direndam selama 24 jam bervariasi antara $0,78 \%$ sampai $1,26 \%$. Semua nilai pengembangan tebal papan komposit pada penelitian ini memenuhi standar JIS A 5908 (1994) yang mensyaratkan pengembangan tebal selama 24 jam maksimum $12 \%$. Hasil sidik ragam menunjukkan bahwa ukuran sabut kelapa tidak berpengaruh nyata terhadap pengembangan tebal papan komposit yang direndam selama 2 jam dan 24 jam.

Bila dibandingkan dengan papan komposit pada penelitian Setyawati dan Massijaya (2005), yang menggunakan sabut kelapa berukuran $5 \mathrm{~cm}$ tanpa penambahan pelapis dengan nilai pengembangan tebal $0,47 \%$ (2 jam) dan 0,78\% (24 jam), maka papan komposit pada penelitian ini memiliki pengembangan tebal yang lebih besar setelah direndam selama 24 jam. Hal ini disebabkan finir yang digunakan sebagai pelapis pada permukaan papan komposit lebih mudah menyerap air, sehingga berpengaruh terhadap pengembangan tebal papan. Namun dari Gambar 3 dan 4 dapat dilihat bahwa pengembangan tebal papan komposit pada penelitian ini tidak berbanding lurus terhadap penyerapan airnya. Hal ini disebabkan pada papan komposit ini terdapatnya rongga-rongga kosong yang memungkinkan air masuk pada saat perendaman, tetapi partikel sabut kelapa tidak seluruhnya mengembang karena tertutup oleh plastik yang hidrofobik.

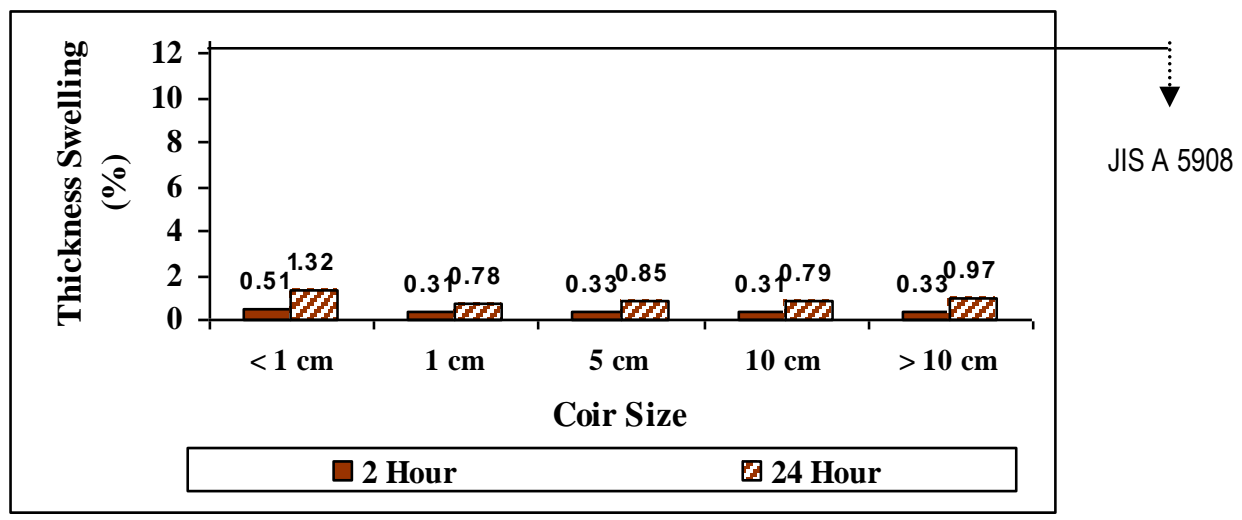

Figure 4. Thickness Swelling of the Composite Board after 2 and 24 Hour Water Immersion at Different Coir Sizes 


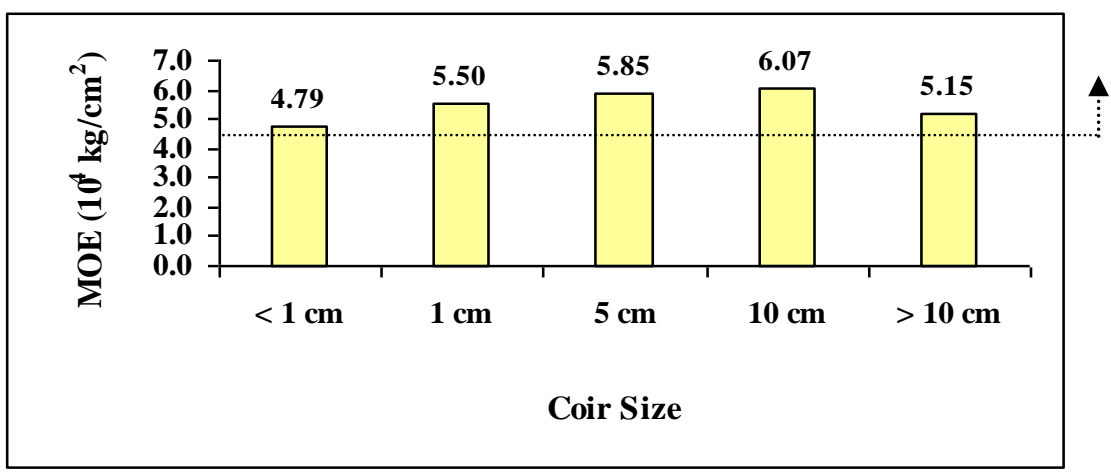

Figure 5. MOE of the Composite Board at Different Coir Sizes

Sifat pengembangan tebal merupakan salah satu sifat fisis yang menunjukkan stabilitas dimensi papan komposit. Bila pengembangan tebal rendah, berarti stabilitas dimensinya tinggi. Tingginya stabilitas dimensi papan komposit yang dibuat dengan perekat plastik disebabkan sifat plastik yang hidrofobik. Dengan demikian papan komposit yang dihasilkan cenderung memiliki sifat hidrofobik juga, sehingga lebih tahan terhadap air.

\section{Sifat Mekanis}

\section{Modulus Lentur (Modulus of Elasticity (MOE))}

Modulus elastisitas papan komposit yang dihasilkan berkisar antara $4,79 \times 10^{4} \mathrm{~kg} / \mathrm{cm}^{2}$ hingga $6,07 \times 10^{4} \mathrm{~kg} / \mathrm{cm}^{2}$. Nilai rata-rata modulus elastisitas papan komposit disajikan pada Gambar 5.

Nilai modulus elastisitas papan komposit cenderung meningkat sampai ukuran sabut kelapa $10 \mathrm{~cm}$, namun setelah itu nilainya menurun. Pada umumnya semakin panjang atau besar ukuran partikel yang digunakan, keteguhan lentur papan komposit juga akan semakin tinggi. Hal ini disebabkan luas bidang rekat partikel menjadi lebih kecil sehingga perekat dapat bekerja secara optimal. Selain itu partikel sabut kelapa yang lebih panjang memilkii slenderness ratio yang cukup besar, sehingga kemungkinan terjadi ikatan yang saling menjalin antara partikel-partikel sabut kelapa tersebut. Dengan demikian kontak antar partikel juga lebih rapat, sehingga kekuatan papan komposit juga lebih tinggi.

Pada penelitian ini menurunnya modulus elastisitas papan komposit yang dibuat dengan menggunakan sabut kelapa utuh (panjang 15 sampa1 $20 \mathrm{~cm}$ ) kemungkinan disebabkan oleh penyebaran plastik PE daur ulang yang kurang sempurna. Hal ini disebabkan sabut kelapa dengan ukuran yang terlalu panjang memilki bulk density yang lebih besar, sementara perekat yang digunakan berupa pelet, sehingga dengan proses pembuatan secara manual kondisi pencampuran yang sempurna lebih sukar dilakukan. Ini berbeda apabila perekat yang digunakan berbentuk cairan, karena perekat dapat lebih mudah diaplikasikan. Salah satu alternatif yang dapat ditempuh untuk mengatasi hal ini adalah dengan menggunakan plastik daur ulang berbentuk serbuk, sehingga plastik dapat tercampur lebih merata. Walaupun nilai modulus elastisitas papan komposit yang dihasilkan bervariasi pada berbagai ukuran sabut kelapa, namun hasil sidik ragam menunjukkan bahwa ukuran partikel sabut kelapa tidak berpengaruh nyata terhadap modulus elastisitas.

Berdasarkan standar JIS A 5908, nilai MOE papan berlapis finir pada sejajar arah panjang papan minimal adalah $4,59 \times 10^{4}$ $\mathrm{kgf} / \mathrm{cm}^{2}$, dengan demikian pada penelitian ini semua papan komposit yang dihasilkan dapat memenuhi standar tersebut. Bila dibandingkan dengan papan komposit dari sabut kelapa dan plastik daur ulang tanpa penambahan finir yang diperoleh pada penelitian Setyawati dan Massijaya (2005), maka peningkatan modulus lentur papan komposit pada penelitian ini mencapai 5,3 kali. Selain itu dengan adanya bahan pelapis penampilan papan komposit yang dihasilkan juga menjadi lebih menarik.

\section{Keteguhan Patah (Modulus of Rupture (MOR))}

Nilai rata-rata keteguhan patah papan komposit berkisar antara $422 \mathrm{~kg} / \mathrm{cm}^{2}$ hingga 493 $\mathrm{kg} / \mathrm{cm}^{2}$, disajikan pada Gambar 6. Modulus patah papan komposit cenderung makin tinggi dengan makin panjangnya ukuran sabut kelapa, sebagaimana yang terjadi pada modulus elastisitas. Namun, dari hasil sidik ragam diketahui bahwa ukuran sabut kelapa tidak 


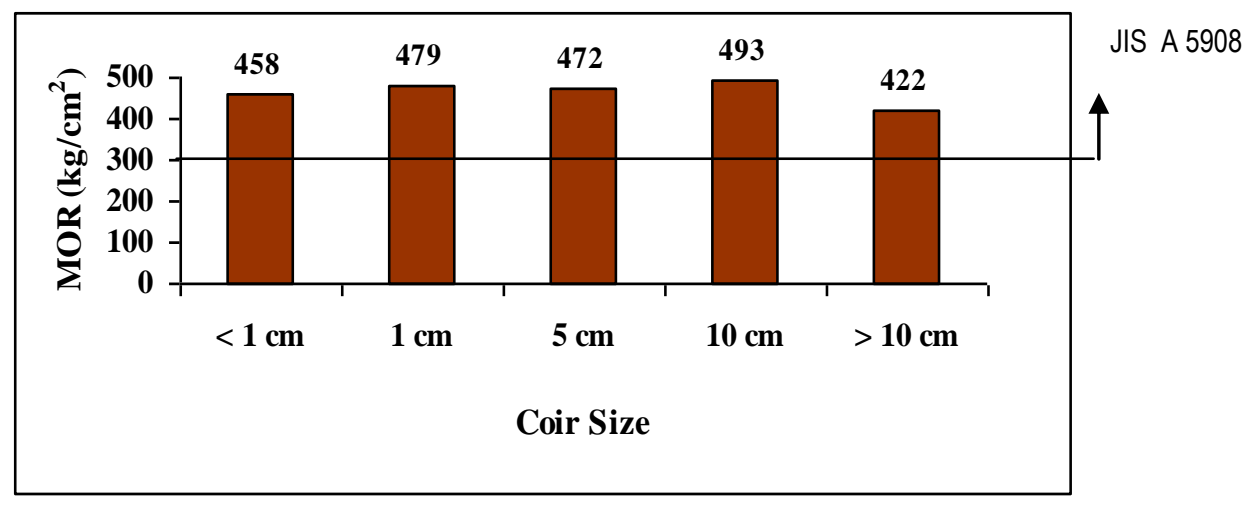

Figure 6. MOR of the Composite Board at Different Coir Sizes

berpengaruh nyata terhadap keteguhan patah papan komposit.

Berdasarkan standar JIS A 5908, nilai MOR pada searah panjang papan untuk tipe papan berlapis finir minimal $306 \mathrm{kgf} / \mathrm{cm}^{2}$, dengan demikian semua nilai modulus patah papan komposit pada penelitian ini telah memenuhi standar tersebut.

\section{Keteguhan Tarik Tegak Lurus Permukaan (Internal Bond)}

Nilai rata-rata keteguhan tarik tegak lurus permukaan papan komposit berkisar antara 4,71 $\mathrm{kg} / \mathrm{cm}^{2}$ hingga $7,77 \mathrm{~kg} / \mathrm{cm}^{2}$ disajikan pada Gambar 7. Keteguhan tarik tegak lurus permukaan papan komposit cenderung meningkat dengan makin panjangnya ukuran sabut kelapa, sampai batas 10 $\mathrm{cm}$. Pola tersebut sama seperti yang terjadi pada modulus elastisitas dan keteguhan patah. Namun, dari hasil sidik ragam diketahui bahwa ukuran sabut kelapa tidak berpengaruh nyata terhadap keteguhan rekat papan komposit.

Berdasarkan standar JIS A 5908, nilai keteguhan rekat pada searah panjang papan untuk tipe papan berlapis finir minimal $3,1 \mathrm{~kg} / \mathrm{cm}^{2}$, dengan demikian semua nilai keteguhan tarik tegak lurus permukaan papan komposit pada penelitian ini telah memenuhi standar tersebut.

\section{KESIMPULAN}

Papan komposit berlapis finir dari sabut kelapa dan plastik polietilena daur ulang pada penelitian ini belum memenuhi semua kriteria yang ditetapkan dalam standar JIS A 5908 (1994). Akan tetapi sifat fisis papan komposit seperti kerapatan dan pengembangan tebal, serta sifat mekanis yang meliputi modulus elastisitas, keteguhan patah, dan kekuatan tarik tegak lurus permukaan telah memenuhi standar tersebut.

Secara umum perbedaan ukuran partikel sabut kelapa pada penelitian ini tidak berpengaruh nyata terhadap kualitas papan komposit. Dengan demikian dalam pembuatan papan komposit selanjutnya, penggunaan ukuran sabut kelapa lebih difokuskan pada segi efisiensi dan kemudahan dalam pengerjaannya. Berdasarkan hal tersebut serta sifat-sifat papan komposit yang dihasilkan pada penelitian ini, maka penggunaan sabut kelapa dengan panjang $5 \mathrm{~cm}$ adalah yang paling optimum.

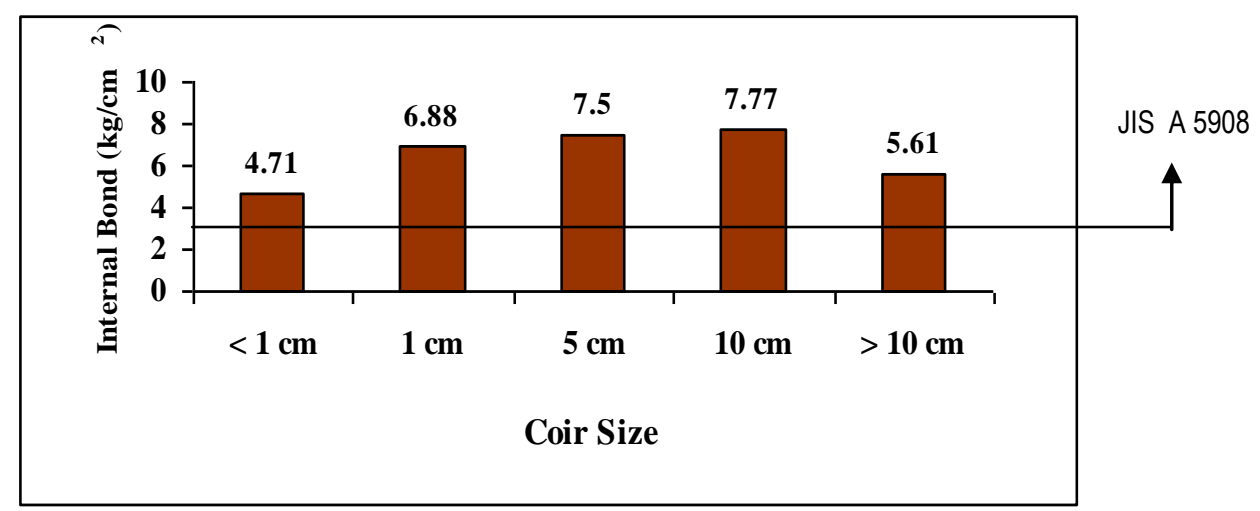

Figure 7. Internal Bonding of the Composite Board at Different Coir Sizes 


\section{DAFTAR PUSTAKA}

FAO. 1999. Improvement in Drying, Softening, Bleaching, Dyeing Coir Fibre/Yarn and in Printing Coir Floor Coverings. www.fao.org/documents/show_cdr.asp?url_file $=/$ DOCREP/005/Y3612E/y3612e03.htm Maret 2006)

Febrianto F., D Setyawati, M Karina, E S Bakar, and Y S Hadi. 2006. Influence of wood flour and modifier content on the physical and mechanical properties of woodflour-recyle polypropylene composites. Journal of Biological Sciences 6 (2): 337-343

Guo W., T Okammoto, M Takatani, W Zheng. 2004. Evironmental friendly wood/polylactic acid composites. In : Proceeding of The $7^{\text {th }}$ Pacific Rim Bio-Based Composites Symposium Vol.II. Nanjing October 31 - November 2 2004. p 248-257

[JSA] Japanese Standards Association. 1994. Particleboards. Japenese Industrial Standar (JIS) 5908-1994. Japan.

Mulyadi. 2001. Sifat-sifat Papan Partikel dari Limbah Kayu dan Plastik. [Skripsi] Jurusan Teknologi Hasil Hutan Fak. Kehutanan IPB.

Massijaya. 2001. Pengembangan Papan Komposit Dari Limbah Kayu dan Plastik. Bogor :
Laporan Penelitian Hibah Bersaing VII Perguruan Tinggi, Fakultas Kehutanan IPB.

Nuryawan, A. and M Y Massijaya. 2005. Development of Exterior Composite Plywood (Com-ply) Product Made of Meranti Veneer and Ekaliptus (Eucalyptus deglupta Blume) Thinning Volume. Peronema Forestry Science Journal 1 (2): 50-54

Setyawati, D. dan M Y Massijaya. 2005. Pengembangan Papan Komposit Berkualitas Tinggi dari Sabut Kelapa dan Plastik Polipropilena Daur Ulang (I) : Suhu dan Waktu Kempa Panas. Makalah dipresentasikan pada seminar MAPEKI VIII, Tenggarong 3 - 5 September 2005

Suhasman, M. Y. Massijaya, Y.S. Hadi. 2005. The effect of face and back layer types on composite board quality. Proceedings of the $6^{\text {th }}$ International Wood Science Symposium LIPI-JSPS Core University Program in the Field of Wood Science. Bali August 29-31, 2005. Pp. 241-247.

Walhi. 2004. Hutan Hancur, Moratorium Manjur. http://www.walhi.or.id (14 Desember 2005)

Diterima : 15 Mei 2006

Dina Setyawati

Mahasiswa Program Doktor, PS IImu Pengetahuan Kehutanan

Sekolah Pasca Sarjana IPB

(Staf Pengajar Fakultas Kehutanan Universitas Tanjungpura, Pontianak)

Yusuf Sudo Hadi dan Muh. Yusram Massijaya

Lab. Bio Komposit, Departemen Hasil HUtan

Fakultas Kehutanan IPB, Kampus Darmaga Bogor

Naresworo Nugroho

Lab. Keteknikan Kayu, Departemen Hasil HUtan

Fakultas Kehutanan IPB, Kampus Darmaga Bogor 